УДК 330.12

ББК 65.31

ПОНЯТИЕ СТРОИТЕЛЬСТВА КАК ВИДА ЭКОНОМИЧЕСКОЙ ДЕЯТЕЛЬНОСТИ

\author{
О. С. ГОЛУБОВА \\ holubava@bntu.by \\ кандидат экономических наук, доцент, \\ заведующий кафедрой «Экономика строительства» \\ Белорусский национальный технический университет \\ Минск, Республика Беларусь
}

\begin{abstract}
В контексте развития науки и технологий, насыщения рынка и повышения уровня требований потребителей к возводимым объектам строительства рассмотрено понятие строительства, как вида экономической деятельности. Это позволило: 1) показать, что основной целью развития строительного комплекса является создание современных энергоэффективных и ресурсоэкономичных, экологически безопасных, доступных и комфортных зданий и сооружений; 2) обосновать необходимость учета в определении понятия строительства повышение качественных характеристик среды жизнедеятельности; 3) уточнить понятие «строчтельства, как вида экономической деятельности» и ввести в оборот категории «качественные характеристики среды жизнедеятельности».
\end{abstract}

Ключевые слова: строительство, вид экономической деятельности, доступные и комфортные здания и сооружения, цели и задачи развития строительства.

\title{
CONSTRUCTION AS ECONOMIC ACTIVITY
}

\author{
V. S. HOLUBAVA \\ $\mathrm{PhD}$ in Economics, Associate Professor, \\ Head of the Department «Economics in Civil Engineering» \\ Belarusian National Technical University \\ Minsk, Republic of Belarus
}

In the context of science and technology development, the market saturation and increase of customer requirements for construction projects, construction is considered as economic activity. It allows: 1) to show that the main goal of the development of the construction complex is a creation of modern energy-efficient and resource-saving, ecologocally safe, accessible and comfortable buildings and structures; 2) to justify the need taking into account in the definition of the construction an increase in the habitat's qualitative characteristics; 3) clarify the notion of "construction as economic activity" and introduce into the turnover "qualitative characteristics of the habitat".

Keywords: construction, economic activity, affordable and comfortable buildings and structures, the goals and objectives of construction development.

\section{ВВЕДЕНИЕ}

Настоящее время характеризуется развитием техники и технологий, высоким уровнем материальной обеспеченности населения в целом, и объектами строительства в частности. Для дальнейшего развития отрасли и привлечения средств в строительство 
требуется рассматривать этот вид экономической деятельности не столько с позиции создания материальных благ, сколько с позиции строительства объектов, имеющих высокую потребительскую стоимость, обеспечивающих опережающее развитие территорий и регионов. В этом плане необходимо пересмотреть понятие строительства, как вида экономической деятельности, что позволит сформировать основные задачи стратегического развития строительства и определить пути их решения.

\section{РЕЗУЛЬТАТЫ И ИХ ОБСУЖДЕНИЕ}

Рассмотрению проблем развития строительной отрасли посвящены научные труды многих российских исследователей. Так В. В. Бобылев рассматривает организационные проблемы управления реализацией инвестиционно-строительных проектов на постприватизационном экономическом пространстве, методы оценки эффективности, выбора и организационных форм управления строительством [1]. Диссертационная работа О. А. Омарова посвящена методологическим основам повышения эффективности управления предприятиями строительного комплекса [2]. Теория и методология стратегического управления развитием промышленного строительства в регионе, а также влияние инвестиционно-строительной деятельности на развитие территорий рассмотрены в работах В. Г. Полякова [3] и И. Л. Владимировой [4]. П. Б. Люлин [5] сконцентрировал свое исследование на совершенствовании регулирования инвестиционно-строительной деятельности субъектов строительства и всего строительного комплекса. Вопросы государственного регулирования строительной деятельности и отдельных ее аспектов широко рассматриваются учеными и специалистами Беларуси $[6 ; 7 ; 8]$. Однако, обобщенного понятия строительства, как вида экономической деятельности, эти работы не раскрывают.

Если рассматривать строительство в широком смысле слова, то Толковый словарь русского языка С. И. Ожегова, Н. Ю. Шведова определяет строительство как «1. Отрасль науки и техники, занимающаяся возведением и реконструкцией зданий, сооружений. 2. Возведение зданий и сооружений. 3 . То же что стройка. 4. Создание, организация чегонибудь» [9, с. 774]. В данном понятии на первом месте стоит отнесение строительства к самостоятельной отрасли науки и техники, что определяет его уникальность с точки зрения научных исследований и значимость с точки зрения возведения и реконструкции зданий, сооружений.

Как область науки и техники строительство является отраслью материального производства. Общегосударственный классификатор Республики Беларусь ОКРБ 005 2011 «Виды экономической деятельности» (ОКЭД) выделяет строительство отдельной секцией F. «Секция охватывает общестроительные и специальные работы по строительству зданий, сооружений и иных объектов строительства. Сюда относятся новое строительство (в том числе возведение зданий и сооружений из сборных конструкций на месте ведения работ, строительство временных зданий и сооружений, а также строительство завершенных зданий и сооружений из готовых блочных конструкций или элементов собственного производства), реконструкция (модернизация), ремонт зданий и сооружений, реставрационные работы» [10].

То есть для статистики строительство классифицируется на основании отнесения работ к отдельным видам строительной деятельности. Кроме того, ОКРБ 005-2011, в соответствии с которым ведется государственная статистика в области строительства, определяет, что «К данной секции также относится реализация проектов по строительству зданий и сооружений путем объединения финансовых, технических и физических средств. Если данные работы проводятся с целью последующей эксплуатации объектов 
(например, аренды помещений в этих зданиях, осуществления производственной деятельности на этой территории), то в таком случае объект не будет классифицироваться в данной секции, то есть будет рассматриваться в другой секции в соответствии с планируемым к осуществлению видом деятельности, например, операции с недвижимостью, производство и т. д.».

Таким образом с точки зрения классификации по видам экономической деятельности для статистики выполнение работ для собственных нужд, хозяйственный способ строительства, относятся к другим видам экономической деятельности. Кроме того, строительство, выполняемое организаций собственными силами для собственных нужд, имеет специфику бухгалтерского учета и статистической отчетности.

Для определения строительства как вида экономической деятельности, важна целевая направленность на экономический результат. И хотя сами результаты строительной деятельности в классификаторе не обозначены, к строительной деятельности относятся только те работы, которые выполняются для реализации другим субъектам хозяйствования.

В Законе «Об архитектурной, градостроительной и строительной деятельности в Республике Беларусь» (далее - Закон № 300-3) дано следующее определение понятия «строительство»: «Строительная деятельность (строительство) - деятельность по возведению, реконструкции, ремонту, реставрации, благоустройству объекта, сносу, консервации не завершенного строительством объекта, включающая выполнение организационно-технических мероприятий, в том числе оказание инженерных услуг в строительстве, подготовку разрешительной и проектной документации, выполнение строительно-монтажных, пусконаладочных работ» [11]. В определении понятия «строительство» указаны виды экономической деятельности, относящиеся к строительству. Преимуществом определения, данного в Законе «Об архитектурной, градостроительной и строительной деятельности в Республике Беларусь», распространяющемся на правоотношения в области архитектурной, градостроительной и строительной деятельности, является то, что в нем детально расписаны виды строительной деятельности, подпадающие под определение строительства. Кроме того, закон не ограничивает сферу строительства в зависимости от того, для каких целей осуществляется строительство. Вся деятельность, соответствующая перечню видов строительной деятельности, приведенной в законе, относится к строительству.

В Градостроительном кодексе Российской Федерации строительство определено, как «создание (возведение) зданий, строений и сооружений» [12]. В этом определении акцент сделан на результаты строительной деятельности - здания, строения, сооружения и не говорится о видах строительной деятельности, и ее целевой направленности.

В нормативных документах Республики Беларусь объектами строительства выступают здания и сооружения. «Здание - архитектурное сооружение, постройка, дом» [9, с. 277]. В целом под зданием понимается строение с внутренним пространством (помещениями), используемым людьми. «Сооружение - всякая значительная постройка» [9, с. 747]. Сооружение - это любой объект, созданный в результате строительного производства, не являющийся зданием. Это объемная, плоскостная или линейная строительная система, имеющая наземную, надземную и (или) подземную части и предназначенная для выполнения производственных процессов различного вида, хранения продукции, временного пребывания людей, перемещения людей и грузов. «Строение - здание, постройка» [9, с. 774]. Строение - результат строительства, общий термин, который объединяет и здания, и сооружения. Таким образом, правильно объектами строительной деятельности называть здания и сооружения.

Строительство, являясь отраслью материального производства, в которых создаются материальные блага, удовлетворяет определенные потребности человека, личные 
или общественные. То есть по нашему мнению более точно строительную деятельность (строительство), как вид экономической деятельности, следует трактовать как удовлетворение потребностей человека в зданиях и сооружениях путем выполнения деятельности по возведению, реконструкции, ремонту, реставрации, благоустройству объекта, сносу, консервации не завершенного строительством объекта, включающую выполнение организационно-технических мероприятий, в том числе оказание инженерных услуг в строительстве, подготовку разрешительной и проектной документации, выполнение строительно-монтажных, пусконаладочных работ.

В этом определении заключаются три главные характеристики строительства, как вида экономической деятельности:

- удовлетворение потребностей. Строительство может выступать видом экономической деятельности только тогда, когда появляется продукт, обеспечивающий удовлетворение той или иной потребности человека, продукт имеющий потребительскую стоимость. И поскольку объекты строительства имеют длительный жизненный цикл, то вопрос продажи, обмена объектов строительства - это вопрос времени. Кроме того, даже созданный для собственного использования объект имеет потребительскую стоимость, облагается налогом на недвижимость, выступает объектом залога, обеспечивает удовлетворение потребностей и экономических интересов;

- объекты строительства: здания и сооружения. Строительство, как вид материального производства создает объекты материального мира, которые имеют материально-вещественную форму и, как правило, длительный жизненный цикл. Строительство обеспечивает создание зданий и сооружений и восстановление их потребительских свойств, утрачиваемых в течение жизненного цикла;

- виды строительной деятельности. К строительной деятельности относится деятельность по возведению, реконструкции, ремонту, реставрации, благоустройству объекта, сносу, консервации не завершенного строительством объекта, включающая выполнение организационно-технических мероприятий, в том числе оказание инженерных услуг в строительстве, подготовку разрешительной и проектной документации, выполнение строительно-монтажных, пусконаладочных работ. Подробный перечень видов строительной деятельности четко очерчивает сферу строительства, отделяя от сферы технической эксплуатации, инвестиционной и производственной деятельности, что позволяет однозначно выделять виды деятельности, составляющие строительство и ему сопутствующие.

Делая акцент на удовлетворение потребностей человека в зданиях и сооружениях, следует более подробно рассмотреть какие потребности человека удовлетворяет строительство. В настоящее время существует множество научных исследований, посвященных изучению потребностей, как мотиву экономической деятельности. Труды Е. Н. Балыко, С. П. Богачева, М. Ф. Гуськовой, В. Н. Логунова, Г. М. Россинской посвящены изучению потребностей человека, их иерархии и трансформации в современных условиях социальноэкономического развития. Наибольшую популярность имеет иерархическая модель потребностей человека американского психолога Абрахама Маслоу [13]. Согласно этой модели потребности, можно разделить на пять основных категорий:

1. Физиологические: голод, жажда, половое влечение и т. д.

2. Потребности в безопасности: комфорт, постоянство условий жизни.

Строительство зданий и сооружений и обеспечивает удовлетворение потребности в безопасности, комфорте, человека. Для удовлетворения этой потребности главными характеристиками объектов строительства выступают: надежность, комфортность, долговечность, экологичность, доступность. 
3. Социальные: социальные связи, общение, привязанность, забота о другом и внимание к себе, совместная деятельность.

Здания и сооружения обеспечивают строительство сетей связи, коммуникаций, обеспечивают условия для взаимодействия и добрососедства, производственной и бытовой совместной деятельности и эти их качества удовлетворяют соответствующие потребности. Люди склонны привязываться, любить свое жилье, свое место работы, поскольку проводят там большую часть своей жизни.

4. Престижные: самоуважение, уважение со стороны других, признание, достижение успеха и высокой оценки, служебный рост.

Здания и сооружения могут быть разного уровня качества. Высококачественные здания и сооружения формируют отношения престижа, признания и высокой оценки для их пользователей. Поэтому физические лица и организации, желающие подчеркнуть свой уровень заказывают индивидуальные объекты, уникальные, вызывающие большой интерес и признание.

5. Духовные: познание, самоактуализация, самовыражение, самоидентификация.

Для архитекторов, строителей, заказчиков строительство объектов может выступать инструментом самовыражения, творчества, искусства и культуры. Объекты архитектуры и строительства могут быть объектами культурного и исторического наследия, или объектами футуристическими, неординарными и в этом отношении ценность таких объектов очень высока. Ценность уникальных зданий и сооружений для общества заключается в том, что они являются центрами культуры и искусства, способны обеспечивать туристическую привлекательность, быть центрами формирования доходов для отдельных населенных пунктов и регионов.

Первые два вида потребностей относятся к первичным потребностям, удовлетворяющим физиологические потребности человека. Удовлетворение этих потребностей жизненно-важно для человека. Потребности третьего, четвертого и пятого уровней относятся к высшим потребностям, культурным потребностям.

В соответствии с Концепцией развития строительного комплекса Республики Беларусь на 2011 - 2020 годы «основной целью развития строительного комплекса является создание современных энергоэффективных и ресурсоэкономичных, экологически безопасных зданий и сооружений, новых конкурентоспособных на внутреннем и внешних рынках строительных материалов, не уступающих по своему качеству европейским» [14].

То есть в Концепции целевым направлением установлено удовлетворение первичных потребностей населения. Для достижения этой цели Концепцией «предусматривается решение следующих задач:

- внедрение инновационных технологий, обеспечивающих производство строительной продукции ресурсосберегающего типа;

- достижение европейского качества выпускаемой строительной продукции (работ, услуг) за счет обновления основных производственных средств и внедрения инновационных технологий;

- развитие строительства доступного, комфортного и энергоэффективного жилья;

- поддержка индивидуального строительства, развитие строительства в сельской местности и малых городах, в том числе децентрализация застройки г. Минска и развитие городов-спутников;

- предоставление земельных участков и инфраструктуры для массовой и индивидуальной застройки;

- создание необходимых объектов социальной инфраструктуры» [14].

Все задачи, которые ставятся перед строительным комплексом ориентированы на достижение заявленных целей и удовлетворение первичных потребностей. В то же 
время сейчас в связи с ростом уровня материального благосостояния происходит смещение акцентов на удовлетворение культурных потребностей. И в настоящее время конкурентоспособность строительного комплекса в целом, отдельных организаций, выполняющих функции заказчиков, подрядчиков, проектировщиков в строительной деятельности должна ориентироваться на создание таких зданий и сооружений, которые обеспечивают удовлетворение социальных, престижных и духовных потребностей отдельных граждан, коллективов, и общества в целом.

Для повышения качественных характеристик зданий и сооружений, важно процессы строительства и эксплуатации рассматривать как единое целое. Создание объектов, независимо от того создаются они на продажу и для собственного использования, должно быть ориентировано на повышение потребительских характеристик объектов недвижимости. В этом ключе следует рассматривать участников строительной деятельности с точки зрения их заинтересованности в повышении потребительских свойств возводимых объектов. Это имеет особое значение для строительной отрасли, поскольку здания и сооружения имеют длительный срок эксплуатации, а уровень жизни и, и соответственно требования потребителей, постоянно растут. При проектировании и строительстве объектов следует ориентироваться не на требования сегодняшнего дня, а учитывая фактор возрастающих потребностей, предусматривать повышение требований потребителей к объектам недвижимости на перспективу.

Увеличение потребительских свойств зданий и сооружений оказывает прямое влияние на потребительскую стоимость, обеспечивает долгосрочный спрос на объекты недвижимости. При продаже объектов недвижимости продается не здание или сооружение, а среда жизнедеятельности. Ее эстетические, комфортные, экологические характеристики, безопасные условия, обеспечивающие гармоничное развитие личности, определяют потребительскую стоимость объекта недвижимости в настоящее время в значительно большей степени, чем характеристики надежности и долговечности. Обеспечение надежности и безопасности - обязательные требования, которые имеют первостепенную значимость для зданий и сооружений. Их значимость и безусловность не подвергается сомнению. Однако наличие только этих качественных характеристик в настоящее время недостаточно, и основные цели развития строительного комплекса должны быть скорректированы.

С учетом всего вышесказанного предлагается следующая формулировка цели и задач развития строительного комплекса Республики Беларусь: основной целью развития строительного комплекса является создание современных энергоэффективных и ресурсоэкономичных, экологически безопасных доступных и комфортных зданий и сооружений, соответствующих возрастающим потребностям населения в повышении качественных характеристик среды жизнедеятельности, новых конкурентоспособных на внутреннем и внешних рынках строительных материалов, обеспечивающих высокое качество зданий и сооружений.

В этом определении целей, в отличие от существующего устанавливается целевая ориентация строительства на удовлетворение потребностей населения повышении качественных характеристик среды жизнедеятельности, что позволяет оценивать эффективность строительства не только по техническим параметрам качества, таким как энергоэффективность, ресурсоэкономичность, экологическая безопасность, но и по уровню комфортности, эстетичности, способности удовлетворять требованиям развития личности и общества в целом. Еще одним отличием предлагаемой автором цели от существующей является формирование требований к строительным материалам, не просто не уступать своему качеству европейским, а обеспечивать высокое качество зданий и сооружений. При этом не устанавливается определенных требований сравнения качественных 
характеристик строительных материалов с европейскими, японскими, американскими или другими нормами. Конкурентоспособность на внутреннем и внешних рынках определяет характеристики качества строительных материалов, необходимые для успешного конкурирования на разных рынках.

С учетом предлагаемой автором формулировки цели развития строительного комплекса, и обеспечивающие достижение этой цели задачи, предлагается сформулировать следующим образом:

- создание современных энергоэффективных и ресурсоэкономичных, экологически безопасных, доступных и комфортных зданий и сооружений, соответствующих возрастающим потребностям населения в повышении качественных характеристик среды жизнедеятельности;

- поддержка индивидуального строительства, развитие строительства в сельской местности и малых городах, в том числе децентрализация застройки г. Минска и развитие городов-спутников;

- внедрение инновационных технологий, обеспечивающих производство конкурентоспособной строительной продукции;

- производство новых конкурентоспособных на внутреннем и внешних рынках строительных материалов, обеспечивающих высокое качество зданий и сооружений.

В этих задачах на первый план выходит задача создания современных энергоэффективных и ресурсоэкономичных, экологически безопасных зданий и сооружений, соответствующих возрастающим потребностям населения в повышении качественных характеристик среды жизнедеятельности, которая, в отличие от существующих, устанавливает требования по энергоэффективности, ресурсоэкономичности, экологичности, доступности и комфортности ко всем зданиям и сооружениям, а не только к объектам жилищного строительства. Кроме того, основной задачей выступает создание среды жизнедеятельности, соответствующей возрастающим потребностям населения в качестве среды жизнедеятельности, что позволяет оценивать результаты строительной деятельности с точки зрения населения, использующего здания и сооружения для труда и отдыха. Эта задача предусматривает единые требования создания всех объектов, как производственного назначения, так и гражданского строительства по единым требованиям. Потому что требования энергоэффективности, ресурсоэкономичности, экологичности, доступности и комфортности должны относиться не только к жилым зданиям, но и к производственным зданиям и сооружениям, зданиям и сооружениям объектов инфраструктуры и социального назначения.

Задача поддержки индивидуального строительства, развития строительства в сельской местности и малых городах, в том числе децентрализация застройки г. Минска и развитие городов-спутников соответствует целевой установке повышения качественных характеристик среды жизнедеятельности и дает конкретные направления ее развития. Поэтому эту задачу, как отдельное направление развития строительного комплекса предлагается оставить без изменений. Эта же задача предусматривает предоставление земельных участков и инфраструктуры для массовой и индивидуальной застройки, как инструмент достижения поставленной задачи.

Достижение целей развития строительного комплекса невозможно без внедрения инновационных технологий, обеспечивающих не просто производство продукции ресурсосберегающего типа, а конкурентоспособной строительной продукции. Конкурентоспособность, как более широкое понятие охватывает значительно больше факторов и позволяет оценить эффективность инновационных технологий точнее, чем ресурсосбережение.

Поскольку строительный комплекс охватывает не только собственно строительство, но и производство строительных материалов, изделий и конструкций, то отдельной 
задачей его развития выступает производство новых конкурентоспособных на внутреннем и внешних рынках строительных материалов, обеспечивающих высокое качество зданий и сооружений. В предлагаемой формулировке производство и использование новых конкурентоспособных материалов напрямую увязывается с качественными характеристиками зданий и сооружений, при строительстве которых они используются, что позволяет увязать разные сферы деятельности строительного комплекса к единой целевой установке, ориентируя все виды деятельности, существующие в строительстве на достижение единой цели.

\section{ВЫВОДЫ}

Уточнение понятия строительства, как вида экономической деятельности, целей и задач строительства необходимо для формирования стратегии развития строительного комплекса. Оно раскрывает социально-экономическую значимость строительства, позволяет сформулировать направления развития и разработать критерии оценки его эффективности. В настоящее время, четкая формулировка задач развития, позволяет в условиях резкого сокращения инвестиций, определять приоритеты для вложения средств в те или иные объекты строительства, сформировать перспективные планы и программы развития строительства как в отраслевом, так и в территориальном разрезе для организаций государственного и частного сектора экономики.

\section{СПИСОК ИСПОЛЬЗОВАННЫХ ИСТОЧНИКОВ}

1. Бобылев, В. В. Организационные проблемы управления реализацией инвестиционно-строительных проектов на постприватизационном экономическом пространстве: автореф дис. ... докт. экон. наук: 08.00.05 / В. В. Бобылев, М. - ГОУ ВПУ «Государственный институт управления», 2011. - 39 с.

2. Омаров, О. А. Методологические основы повышения эффективности управления предприятиями строительного комплекса: автореф дис. ... докт. экон. наук: 08.00.05 / О. А. Омаров, Махачкала. - ООО «Деловой мир», 2010. - 48 с.

3. Поляков, В. Г. Теория и методология стратегического управления развитием промышленного строительства в регионе: автореф дис. ... докт. экон. наук: 08.00.05 / В. Г. Поляков, СПб. - ИзПК СПбГИЭУ, 2011. - 48 с.

4. Владимирова, И. Л. Инвестиционно-строительная деятельность и социальноэкономическое развитие территорий: автореф дис. ... докт. экон. наук: 08.00.05 / И. Л. Владимирова, М. - ГОУ ВПО «Российской экономической академии имени Г. В. Плеханова», 2010. - 41 с.

5. Люлин, П. В. Развитие системы регулирования детальности инвестиционностроительного комплекса: автореф дис. ... докт. экон. наук: 08.00.05 / П. В. Люлин, СПб. Типография «Восстания $-1 », 2015 .-38$ с.

6. Мартынов С. А., Завадская А. Ю. Порядок сдачи выполненных проектно-изыскательских работ. Основания для их оплаты // Строительство и ценообразование. № 1 (9). - 2016. - С. 58-61

7. Голубова, О. С. Проблемы государственного регулирования и пути совершенствования формирования стоимости строительных работ / О. С. Голубова, А. Н. Сидоров // Экономика и управление. - 2014. - № 2 - С. 49-55.

8. Костюкова, С. Н. Развитие интегрированных систем менеджмента в строительстве С.Н. Костюкова // Вестн. Полоц. гос. ун-та. Сер. D. Экон. и юрид. науки. - 2014. № 14. - C. $98-103$. 
9. Ожегов, С. И., Шведов, Н. Ю. Толковый словарь русского языка: 80000 слов и фразеологических выражений / Российская академия наук. Институт русского языка им. В. В. Виноградова - 4-е изд., дополненное. - М.: Азбуковник, 1999. - 944 стр. - С. 774.

10. Общегосударственный классификатор Республики Беларусь. Виды экономической деятельности: ОКРБ 005-2011. - Введ. 05.12.11 (с отменой на территории Республики Беларусь ОКРБ 005-2006). - Минск: Госстандарт, 2011. - 355 с.

11. Об архитектурной, градостроительной и строительной деятельности в Республике Беларусь [Электронный ресурс]: Закон Респ. Беларусь от 5 июля 2004 г. № 300-3: в ред. от 18 июля 2016 г. № 402-3 : с изм. и доп. от 2 мая 2012 г. № 353-3.: [заключено в г. Триесте 10.06.2011 г.] // КонсультантПлюс. Беларусь / ООО «ЮрСпектр», Нац. центр правовой информ. Респ. Беларусь. - Минск, 2017.

12. Градостроительный кодекс Роосийской Федерации [Электронный ресурс]: 29 декабря 2004 г., № 190-Ф3 : принят Гос. Думой 22 дек. 2004 г.: одобр. Советом Федерации 24 дек. 2004 г.: в ред. Федер. закона от 18.06.2017 г. // КонсультантПлюс. Россия / ЗАО «Консультант Плюс». - М., 2017

13. Maslow, A. H. Motivation and Personality. - New York: Harpaer \& Row, 1954.

14. Об утверждении Концепции развития строительного комплекса Республики Беларусь [Электронный ресурс]: постановление Совета Министров Респ. Беларусь, 28 окт. 2010 г., № 1589 КонсультантПлюс. Россия / ЗАО «Консультант Плюс». - М., 2017

\section{REFERENCES}

1. Bobylev, V. V. Organizatsionnyye problemy upravleniya realizatsiyey investitsionno-stroitelnykh proyektov na postprivatizatsionnom ekonomicheskom pro-stranstve: avtoref dis. ... dokt. ekon. nauk: 08.00.05 / V. V. Bobylev. M. - GOU VPU «Gosudarstvennyy institut upravleniya». 2011. $-39 \mathrm{~s}$.

2. Omarov, O. A. Metodologicheskiye osnovy povysheniya effektivnosti uprav-leniya predpriyatiyami stroitelnogo kompleksa: avtoref dis. ... dokt. ekon. nauk: 08.00.05 / O. A. Omarov. Makhachkala. - OOO «Delovoy mir». 2010. - $48 \mathrm{~s}$.

3. Polyakov, V. G. Teoriya i metodologiya strategicheskogo upravleniya razvitiyem promyshlennogo stroitelstva $v$ regione: avtoref dis. ... dokt. ekon. nauk: 08.00.05 / V. G. Polyakov. SPb. - IzPK SPbGIEU. 2011. - 48 s.

4. Vladimirova, I. L. Investitsionno-stroitelnaya deyatelnost i sotsialno-ekonomicheskoye razvitiye territoriy: avtoref dis. ... dokt. ekon. nauk: 08.00.05 / I. L. Vladimirova. M. - GOU VPO «Rossiyskoy ekonomicheskoy akademii imeni G. V. Plekhanova». 2010. - $41 \mathrm{~s}$.

5. Lyulin, P. V. Razvitiye sistemy regulirovaniya detalnosti investitsionno-stroitelnogo kompleksa: avtoref dis. ... dokt. ekon. nauk: 08.00.05 / P. V. Lyulin. SPb. - Tipografiya «Vosstaniya -1». 2015. $-38 \mathrm{~s}$.

6. Martynov, S. A., Zavadskaya, A. Yu. Poryadok sdachi vypolnennykh proyektnoizyskatelskikh rabot. Osnovaniya dlya ikh oplaty // Stroitelstvo i tsenoobrazovaniye. - № 1 (9). 2016. - S.58-61

7. Golubova, O. S. Problemy gosudarstvennogo regulirovaniya i puti sover-shenstvovaniya formirovaniya stoimosti stroitelnykh rabot / O. S. Golubova, A. N. Sidorov // Ekonomika i upravleniye. - 2014. - № 2-S. 49-55.

8. Kostyukova, S. N. Razvitiye integrirovannykh sistem menedzhmenta v stroi-telstve S. N. Kostyukova // Vestn. Polots. gos. un-ta. Ser. D. Ekon. i yurid. nauki. - 2014. - № 14. S. 98-103. 
9. Ozhegov, S. I., Shvedov, N. Yu. Tolkovyy slovar russkogo yazyka: 80000 slov i frazeologicheskikh vyrazheniy / Rossiyskaya akademiya nauk. Institut russkogo yazyka im. V. V. Vinogradova - 4-e izd.. dopolnennoye. - M.: Azbukovnik. 1999. - 944 str. - S. 774.

10. Obshchegosudarstvennyy klassifikator Respubliki Belarus. Vidy ekonomicheskoy deyatelnosti: OKRB 005-2011. - Vved. 05.12.11 (s otmenoy na territorii Respubliki Belarus OKRB 005-2006). - Minsk: Gosstandart. 2011. - 355 s.

11. Ob arkhitekturnoy. gradostroitelnoy i stroitelnoy deyatelnosti v Respublike Belarus [Elektronnyy resurs]: Zakon Resp. Belarus ot 5 iyulya 2004 g. № 300-Z : v red. ot 18 iyulya 2016 g. № 402-Z : s izm. i dop. ot 2 maya 2012 g. № 353-Z.: [zaklyucheno v g. Triyeste 10.06.2011 g.] // KonsultantPlyus. Belarus / OOO «YurSpektr». Nats. tsentr pravovoy inform. Resp. Belarus. - Minsk. 2017.

12. Gradostroitelnyy kodeks Roosiyskoy Federatsii [Elektronnyy resurs] : 29 dekabrya 2004 g.. № 190-FZ : prinyat Gos. Dumoy 22 dek. 2004 g.: odobr. Sovetom Federatsii 24 dek. 2004 g.: v red. Feder. zakona ot 18.06.2017 g. // KonsultantPlyus. Ros-siya / ZAO «Konsultant Plyus». - M.. 2017

13. Maslow, A. H. Motivation and Personality. - New York: Harpaer \& Row. 1954.

14. Ob utverzhdenii Kontseptsii razvitiya stroitelnogo kompleksa Respubliki Belarus [Elektronnyy resurs]: postanovleniye Soveta Ministrov Resp. Belarus. 28 okt. 2010 g.. № 1589 KonsultantPlyus. Rossiya / ZAO «Konsultant Plyus». - M.. 2017

Статья поступила в редакиию 15 января 2018 года. 